\title{
Unresectable Colorectal Carcinoma
}

National Cancer Institute

\section{Source}

National Cancer Institute. Unresectable Colorectal Carcinoma. NCI Thesaurus. Code C162600.

A colorectal carcinoma that is not amenable to surgical resection. 